faith and his early intellectual trajectory, and from which he emerged as a precocious adolescent.

Perhaps surprisingly, Boyle's first exploits as a writer were directed to moral and devotional topics. But at the age of 22 he was "transported and bewitch'd" by experimental chemistry and never looked back. So began a life dedicated to the study of nature: a life that was funded by the substantial means he inherited from his father, and that is epitomized in the title of his popular later work The Christian Virtuoso.

The most compelling chapters in Hunter's narrative cover Boyle's time in Oxford from the winter of 1655-56 and his emergence, in the early 1660s, as a celebrated public figure and emblem of the early Royal Society. These years were his most productive, both in terms of experimental results and written output: from 1660 to 1666, he published a dozen books at an average of 140,000 words per year. Other works took shape in this period, emerging in later decades; and still others have only recently been unearthed and published in the definitive 14-volume The Works of Robert Boyle (Pickering and Chatto, 1999-2000), of which Hunter is an editor.

In his publications, Boyle introduced a new and distinctive natural philosophy called corpuscularianism. He also stressed the interplay of theory and experiment in the construction of natural histories, an approach that was to dominate British science for four decades. However, most significant was the series of innovative experiments Boyle performed with his air-pump, J-tube and long pipette. Through the clever manipulation of air and mercury and with careful measurement, he established that the pressure of the air is inversely proportional to its volume. Furthermore, he solved the longstanding problem in animal physiology as to the cause of air entering the lungs in respiration: there is a differential in air pressure between the expanded lungs and the atmosphere.

Yet there is more to Boyle than the careful experimenter. Hunter shows how in the eyes of his contemporaries, from the royal court to savants abroad, Boyle was a larger-thanlife character. This stemmed in part from his overt religiosity, his reputation for professional integrity and his understated philanthropy. But it is the inner Boyle whom Hunter is most concerned to explore: Boyle the doubter, the vacillator, the stuttering and conscience-stricken man revealed in private notes written near the end of his life. Hunter displays fascination and impartiality, even wavering respect, but in the final analysis it is not clear that he really likes Boyle. However, the biographer shows maturity by leaving the reader latitude to make up their own mind about what made Boyle tick.

This first comprehensive work on the life of Boyle is a piece of stunning scholarship, a command performance by a gifted historian. It is also a great read.

Peter Anstey teaches early modern philosophy at the University of Otago, Dunedin, New Zealand. $\mathrm{He}$ is the author of The Philosophy of Robert Boyle. e-mail: peter.anstey@otago.ac.nz

\title{
Capturing digital lives
}

\section{Total Recall: How the E-Memory Revolution Will Change Everything \\ by Gordon Bell and Jim Gemmell \\ Dutton: 2009.304 pp. $\$ 26.95$}

\section{Delete: The Virtue of Forgetting in the}

Digital Age

by Viktor Mayer-Schönberger

Princeton University Press: 2009.

256 pp. $\$ 24.95$

We are entering an era of unprecedented digital power. Thanks to the diminishing cost of digital storage and the increasing ubiquity of digital devices, the day is coming when we will be able to record almost every interaction we have. Digital microphones will capture our brief encounters with strangers; cameras will snap automatically as we enter new rooms or browse the web. And somewhere on a remote server farm, the images and sounds of our lives will pile

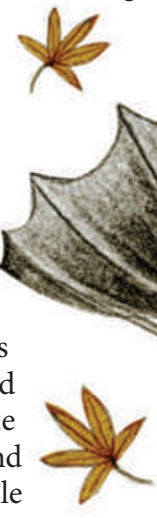
up in a massive database.

On this at least, the authors of two books about the social effects of digital data storage, Total Recall and Delete, agree. Where they differ is in what they think will happen next. Pioneering computer scientist Gordon Bell and his Microsoft colleague Jim Gemmell take a libertarian view in Total Recall. Digital media will free us to dip back into the past at will, they argue. Equipped with information that our brains may have lost, we will act more effectively as individuals in every part of our lives. In Delete, by contrast, information-policy expert Viktor MayerSchönberger believes people and technologies are inextricably woven into the fabric of institutions. Records of our personal data could easily make us vulnerable to the predations of governments and corporations, he warns.

Bell, the first-person narrator of Total Recall, acknowledges the possibility that malefactors might abuse our information, but this is a long way from his primary concern. His book is largely a chronicle of the delight he has experienced in spending the past decade gathering data about himself, a process he calls "lifelogging". At the beginning, this involved simply scanning documents and photographs onto a hard drive.

Then he began to look for ways to capture his experiences as they happened. In 2001, this resulted in the birth of the MyLifeBits project at Microsoft Research. Bell's team,

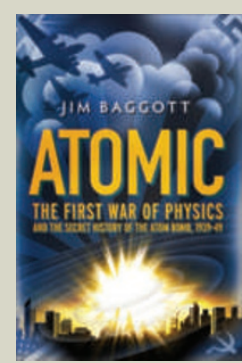

Atomic: The First War of Physics and the Secret History of the Atom Bomb, 1939-49

by Jim Baggot (Icon Books, $€ 9.99$ )

Vividly written and impressively researched, Atomic covers the efforts of scientists and spies in the United States, Britain, the USSR and Nazi Germany to develop their own atomic weapon. Drawing on material including declassified British secret-service transcripts and documents from Soviet archives, this is a thorough but engaging account of the race to build the atomic bomb.

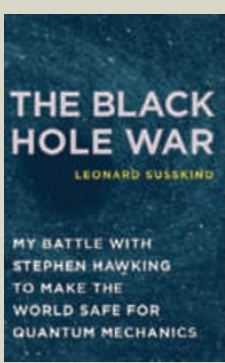

The Black Hole War: My Battle with Stephen Hawking to Make the World Safe for Quantum Mechanics by Leonard Susskind (Little, Brown, £12.99) Leonard Susskind charts his long conflict with Stephen Hawking over the fate of information in a black hole. Paul Davies's review noted it "skilfully explains the subtleties of the physics that underlie the issue, and includes anecdotes to enliven the technical details." (Nature 454, 579-580; 2008.) 
which includes software designer and co-author Jim Gemmell, has developed a suite of digital tools for recording, storing and searching everything from old family photographs to kerbside chats.

Today, Bell wears a 'SenseCam' that automatically takes pictures every time a sensor on the device registers something that he might want recalled: a warm body, or a change in light suggesting a change of place. His desktop computer records his every keystroke. When he travels, a portable Global Positioning System continuously reports his location to MyLifeBits, which among other things allows him to log the time, date and place of any images he takes. Occasionally, he likes to play back these images in rapid-fire succession. "Talk about your life flashing before your eyes!" he enthuses.

With no shortage of hubris, Bell views the sort of tools he and his team are developing as evolutionary scaffolding. Humans are cursed with messy, organic brains that are inclined to forget, he argues. We have tried to mitigate this with memory technologies: first language, then writing, now computing. In fact, Bell asserts, "the arc of human development from the Stone Age through the present can be seen as an ongoing quest for Total Recall".

This, of course, is good news for Microsoft and the MyLifeBits team, who are developing the digital gear that makes such total recall possible. For all Bell's visionary thunder, it is hard not to hear in his writing the voice of the corporate salesman. He and Gemmell have described an imminent techno-utopia in which the technology-enabled individual moves the entire species forward to a new stage of sociotechnical evolution. Yet at ground level, the book mostly offers a simple, plain-spoken

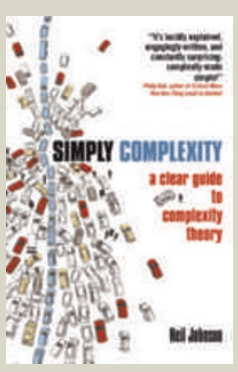

\section{Simply Complexity: A Clear Guide to Complexity Theory}

by Neil Johnson (Oneworld, E9.99)

The science of complexity is still a fledgling field, but one that is on the rise. In this book, Neil Johnson introduces complexity, explaining what it is and how it affects us, before describing how complexity science can be used in a number of ways, from fighting disease to relationships. He also shows how, in the future, it may shed light on our understanding of quantum physics and more.

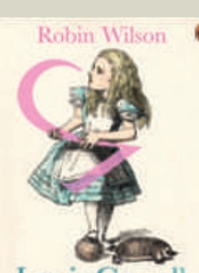

Lewis Carroll in Numberland

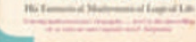

is a construction, built from both personal and social resources.

From this perspective, MayerSchönberger raises questions about the power of technology and how it affects our interpretation of time - a topic that Bell largely ignores. He dramatically undermines Bell's case for the value of being able to behold all the times of our lives at once. He draws on a rich body of contemporary psychological theory to argue that both individuals and societies are obliged to rewrite or eliminate elements of the past that would render action in the present impossible: a job applicant must put their former drug addiction out of their mind, a nation must stop dwelling on the cruelty of its former enemies to make peace. Here lies the central irony of our contemporary technological situation: "Through perfect memory, we may lose a fundamental human capacity - to live and act firmly in the present," he writes.

Mayer-Schönberger also fears that ubiquitous recall technologies would give institutions the power to keep a close eye on us at all times. As a result, individuals would start censoring themselves lest their actions and words be used against them, leading to a kind of social stasis. For him, Bell's proposed solution - security systems that allow users full control over their data - does not go far enough. He will only be satisfied if the devices that store the data are programmed to destroy it regularly and automatically.

If Mayer-Schönberger is right - and I'm convinced he is - then the old Kris Kristofferson song might be true after all: in the future, freedom could be just another word for nothing left to lose.

Fred Turner is assistant professor of communication at Stanford University, Stanford, California 94305-2050, USA, and author of From Counterculture to Cyberculture. e-mail: fturner@stanford.edu

\section{Lewis Carroll in Numberland: His Fantastical Mathematical Logical Life}

by Robin Wilson (Penguin, E9.99)

Although better known for his fiction, Lewis

Carroll's achievements as a mathematician should not be overlooked. Robin Wilson's book "conjures the spirit of a man who delighted in paradox yet insisted on precision ... and who wanted most of all to stump everyone he knew", wrote reviewer Jascha Hoffman (Nature 454, 580-581; 2008). 